\title{
HOW CLOSE ARE GROUND-BASED FABRY-PEROT THERMOSPHERIC WIND AND TEMPERATURE MEASUREMENTS TO EXOSPHERIC VALUES? A SIMULATION STUDY
}

\author{
F. G. McCORMAC, T. L. KILLEEN and B. NARDI \\ Space Physics Research Labotatory, Department of Atmospheric and Oceanic Science, The \\ University of Michigan, Ann Arbor, MI 48109, U.S.A. \\ and \\ R. W. SMITH \\ Geophysical Institute, University of Alaska, Fairbanks. AK 99701, U.S.A.
}

(Received 5 May 1987)

\begin{abstract}
Ground-based Fabry Perot interferometers (FPIs) have been used extensively to determine thermodynamical and hydrodynamical properties of the upper atmosphere by measuring emission line profiles from the $O\left({ }^{3} D\right)$ nightglow at high spectral resolution. The resulting thermospheric winds and temperatures are normally referred to the altitude of the peak of the $O\left({ }^{1} \mathrm{D}\right)$ emission layer, near $250 \mathrm{~km}$, and the effects of wind shear and temperature gradations along the line of sight are neglected. In order to quantify the significance of these effects, and to obtain a better understanding of the "effective" (volumeemission-rate-weighted) altitude of the TPI measurement, a computer simulation of the measurement technique has been performed, incorporating realistic profiles of winds, temperatures and $O\left({ }^{3} D\right)$ volume emission tates along the instrumental line-of-sight. The atmospheric profles used for the simulations are derived from a recently-developed thermospheric computer subroutine based on the predictions of the NCAR thermospheric general circulation model. The simulation code is used to calculate synthetic FPI spectrograms for different viewing geometries and FPI station locations, and the spectrograms are analyzed using standard data reduction techniques to derive fitted winds and temperatures. These are then compared with the atmospheric profiles used as input to the simulation code to determine the effective altitude of each simulated measurement and to study the differences between recovered winds and temperatures and the corresponding exospheric values. A frst investigation using the simulation code for geophysical conditions corresponding to December solstice at solar maximum has indicated that FPI-derived Doppler temperatures may be lower than exospheric temperatures by $\sim 10 \%$ in the winter hemisphere and $\sim 15 \%$ in the summer hemisphere. Furthermore, FPI measurements of neutral winds, particularly at high latitudes, can differ appreciably from exospheric values due to the weighting of the FPI measurement to altitudes near $\sim 250 \mathrm{~km}$.
\end{abstract}

\section{INTRODUCTION}

The thermosphere is that region of the Earth's upper atmosphere above $\sim 90 \mathrm{~km}$ in which the neutral gas temperature increases with altitude to an asymptotic maximum (exospheric) value. Jacchia (1965) and many subsequent authors have described the basic variation of thermospheric temperature with altitude and for different geophysical conditions. In general, the exospheric temperature is reached at altitudes of $\sim 200 \mathrm{~km}$ during solar minimum and $\sim 400 \mathrm{~km}$ during solar maximum, with typical values of $\sim 900$ and $\sim 1600 \mathrm{~K}$, respectively. In addition to the longer-term changes associated with the solar cycle, variations on time scales ranging from hours (e.g. for gravity wave phenomena) to many days (e.g. the 27-day solar rotation period) occur and these correlate with geomagnetic and solar flux indices. Exospheric temperature also varies with location on the globe, with regions of enhanced temperatures occurring at high latitudes where energy sources of magnetospheric origin affect the thermal and dynamical balance of the thermosphere (e.g. Banks, 1977; Killeen and Roble, 1986).

The basic global wind structure in the thermosphere is created by pressure gradients that drive the neutral winds from $\sim 14: 00 \mathrm{~h}$ local solar time (L.S.T.) to $\sim 04: 00$ h L.S.T. At high latitudes, this day-to-night wind is perturbed by frictional and particle heating and is substantially modified by momentum transfer from ions, which typically move in a twin-cell ion convection pattern (e.g. Heppner, 1977; Volland, 1978; Heelis et al., 1982). These ion convection cells map onto the neutral atmosphere to a greater or lesser degree, depending on the time constants for momentum transfer from the convecting ions to the neutral constituents, and give rise to the large-scale neutral thermospheric vortices observed at high latitudes (e.g. 
Roble et al., 1982, 1983, 1984 ; Rees et al., 1983, 1986; Killeen et al., 1984a, b; Killeen and Roble, 1984, 1986; McCormac et al., 1987; Thayer et al., 1987).

The direct measurement of thermospheric neutral temperatures and wind velocities, from the Earth's surface, involves detcrmination of the Doppler shift and Doppler width of naturally-occurring atmospheric emission lines. The Fabry-Perot interferometer (FPl) has been the instrument of choice for this purpose for many years and much has been learned about the hydrodynamical and thermodynamical properties of the thermosphere using the FPI to perform spectral analyses of $630 \mathrm{~nm}$ emission line profiles from thermospheric $O\left({ }^{1} D\right)$, a metastable species that is well thermalized at these altitudes (see reviews by Hernandez and Roble, 1979; Hernandez, 1980; Meriwether, 1983; Hernandez and Killeen, 1987; Killeen, 1987).

Ground-based FPI spectral-line measurements using the $O\left({ }^{1} D\right)$ emission contain information on the thermospheric wind and temperature profiles along the instrument line-of-sight at all altitudes where the emission occurs. The effects of wind shear and temperature gradations within the instrumental field-ofview are typically neglected on the assumption that the observations are so heavily weighted to the emission peak, at a nominal height of $250 \mathrm{~km}$, that the FPI wind and temperature measurements can be assigned uniquely to that altitude. The validity of this assumption for thermospheric temperatures has been tested experimentally by several authors, with somewhat conflicting conclusions. Hernandez et al. (1975) compared ground-based FPI measurements of the nighttime, solar maximum, thermospheric temperature at equatorial latitudes with simultaneous incoherent scatter (IS) radar measurements of electron temperatures at $400 \mathrm{~km}$ altitude. They showed that the FPI measurements from a calculated mean height of $270 \mathrm{~km}$ were $\sim 30 \mathrm{~K}$ lower than the corresponding IS electron temperature measurements, which were assumed to be equal to neutral exospheric temperatures. The difference of $\sim 3.3 \%$ between the reported ground-based FPI temperatures and the IS-derived exospheric temperatures was taken to be indicative of the fact that, at solar maximum, the temperature near the peak of the $O\left({ }^{1} D\right)$ emission is lower than the exospheric temperature. Hays et al. (1970) measured the thermospheric temperature near solar maximum at Ann Arbor, Michigan, with a FPI viewing in a direction towards the Millstone Hill, Massachusetts IS radar site. They showed results from a single night of observations that indicated that the average FPI Doppler temperature was $\sim 45 \mathrm{~K}$ greater than the similarly-averaged IS $F$-region ion temperature, which was assumed to be equivalent to the neutral exospheric temperature for the mid-latitude site. Although the regions of the thermosphere sampled by the two techniques were separated by $\sim 725 \mathrm{~km}$, Hays et al. felt able to conclude that ground-based FPI Doppler temperatures were equivalent to exospheric values. Roble et al. (1968) compared the monthly-averaged FPI Doppler temperature with IS-radar-derived exospheric temperatures for solar minimum conditions and stated that the FPI-derived thermospheric temperature was less than the exospheric value by $25-50$ $K$. Because of the difference in the vertical temperature profile of the thermosphere between solar minimum and solar maximum, discussed below, one would expect the Doppler temperatures to deviate more from exospheric values during solar maximum than during solar minimum. This expectation is not supported uniformly by the published results quoted above.

The peak altitude of the $\mathrm{O}\left({ }^{1} \mathrm{D}\right)$ emission layer can vary by tens of kilometers (Hays et al., 1978) and the interpretation of FPI observations is, therefore, subject to the ambiguity that arises because observed temperature changes may occur due to the rise and fall of the cmission layer as well as duc to local heating effects. Sica et al. (1986) have carefully addressed this issue for situations where aurora were present along the line-of-sight of an FPI at Fairbanks, Alaska. They found that ground-based measurements of Doppler temperatures from a single site were insufficient to infer the height of the emission and, therefore, the altitude to which the measured temperatures should be referred. Sica et al. also presented temperature measurements in the aurora that were significantly lower than the expected exospheric values and ascribed this to the fact that the auroral $O\left({ }^{\prime} D\right)$ emission extends to lower altitudes than the $\mathrm{O}\left({ }^{1} \mathrm{D}\right)$ nightglow emission.

As mentioned above, the exospheric temperature may not be attained until $\sim 400 \mathrm{~km}$ for solar maximum conditions and, therefore, relatively large altitude gradients might be expected to occur for both thermospheric wind and temperature at altitudes near the $O\left({ }^{1} D\right)$ nightglow emission peak at $\sim 250 \mathrm{~km}$. This means that small changes in the altitude of the emission peak result in relatively large changes in the recovered FPI winds and temperatures which may, as a consequence, be erroneously interpreted by the ground-based observers as representing real hydrodynamic or thermodynamic variations (cf. Sica et al., 1986). For solar minimum conditions, on the other hand, the atmosphere is thought to be nearly isothermal above $200 \mathrm{~km}$, and the altitude gradients in wind and temperature near the peak of the $O\left({ }^{1} D\right)$ 
emission are very small. Therefore, the recovered FPI winds and temperatures at solar minimum should be very nearly equivalent to exospheric values.

As a first step towards an improved understanding of the relationship between FPI measurements of winds and temperatures and their corresponding exospheric values and because of the degree of confusion present in the literature regarding the effective altitude of FPI temperature measurements, we have constructed a computer simulation model of the measurement process for solar maximum conditions. The simulation code calculates synthetic FPI spectograms using appropriate viewing geometries and realistic altitude-dependent modelled atmospheric structure (winds, temperatures and volume emission rates) along the instrument line-of-sight. The model atmosphere used as input to the simulation code contains altitude profiles of winds, temperatures, and volume emission rates and is obtained from the vector spherical harmonic (VSH) model of Killeen et al. (1987) which, in turn, is based on the predictions of the National Center for Atmospheric Research (NCAR) thermospheric general circulation model (TGCM) of Dickinson et al. (1981) and Roble et al. (1982). For the work reported here, simulated FPI spectrograms have been analyzed using a standard data reduction technique to provide a set of recovered (fitted) winds and temperatures for various geographic locations. The fitted winds and temperatures have been compared with the input wind and temperature profiles to investigate quantitatively the relationship between the "measured" values and the corresponding exospheric model inputs and to determine the "effective altitude" of each simulated measurement. These comparisons have indicated that FPI-recovered temperatures are $\sim 10 \%$ less than the input exospheric temperatures in the winter hemisphere and $\sim 15 \%$ less in the summer hemisphere for solar maximum conditions and, furthermore, that FPI measurements of neutral winds can differ appreciably (by 100 s of meters per second) from the corresponding exospheric values, particularly at high latitudes, due to the weighting of the observations to altitudes near $250 \mathrm{~km}$ (here, and throughout this paper, the term "exospheric wind" refers to the neutral wind at $\sim 400 \mathrm{~km}$ and above). These latter findings are discussed in the light of experimental measurements of the exospheric wind using averaged data from the Dynamics Explorer-2 (DE-2) spacecraft and correspondingly-averaged line-of-sight thermospheric wind information from the groundbased FPI at Spitsbergen, Norway, for the month of December 1981 (near solar maximum). The experimental results from the two techniques show significant differences for measurements referring to closely-spaced spatial regions. These differences are consistent with and support the results of the simulation study when the differing effective altitudes for the two measurement techniques are taken into account.

The simulation code used to calculate and analyze the synthetic FPI spectrograms is described in Section 2. Section 3 presents the results of our initial study into the FPI measurement process for December solstice, solar maximum conditions, and Section 4 provides a summary of our most important findings.

\section{FPI MEASUREMENT SIMULATION CODE}

The computer program that we have developed to simulate and analyze synthetic FPI spectrograms for various viewing geometries and FPI station locations consists of the following elements : (1) a model atmosphere containing winds, temperatures and $O\left({ }^{1} D\right)$ volume emission rates as a function of altitude, latitude, longitude and Universal Time (U.T.); (2) a numerical representation of an instrument function describing the response of a real FPI to a given spectral signal; (3) a section that approximates the line integral nature of the FPI measurement through the atmosphere by a summation of individual spectrograms, each corresponding to the signal detected from one of a finite set of atmospheric volume elements along the instrument line-of-sight characterized by the appropriate wind, temperature and volume emission rate; (4) a section that uses a standard data reduction technique to analyze the resulting composite spectrogram. We discuss each of these elements of the code in turn.

The first element of the simulation code is an atmospheric model containing profiles of winds and temperatures based on output from the NCAR-TGCM for a solar-maximum, December solstice model run. The model run used was a "diurnally-reproducible" case for a moderate and steady level of geomagnetic activity and incorporating steady magnetospheric forcing of the thermosphere, scaled by a $60 \mathrm{kV}$ crosspolar-cap convection electric field. The NCARTGCM is a three-dimensional, time-dependent model of the thermosphere that has been discussed in detail by Dickinson et al. (1981) and Roble et al. (1982, $1983,1984)$. The particular TGCM model run used has been the subject of several recent studies (Hays et al., 1984; Killeen et al., 1986, 1987) that compared the model predictions with experimental results from the Dynamics Explorer-2 (DE-2) spacecraft. These comparisons have shown that the model winds and temperatures at exospheric altitudes $(\sim 300-400 \mathrm{~km})$ are in good general agreement with the observations. The level of agreement at these altitudes, where global- 

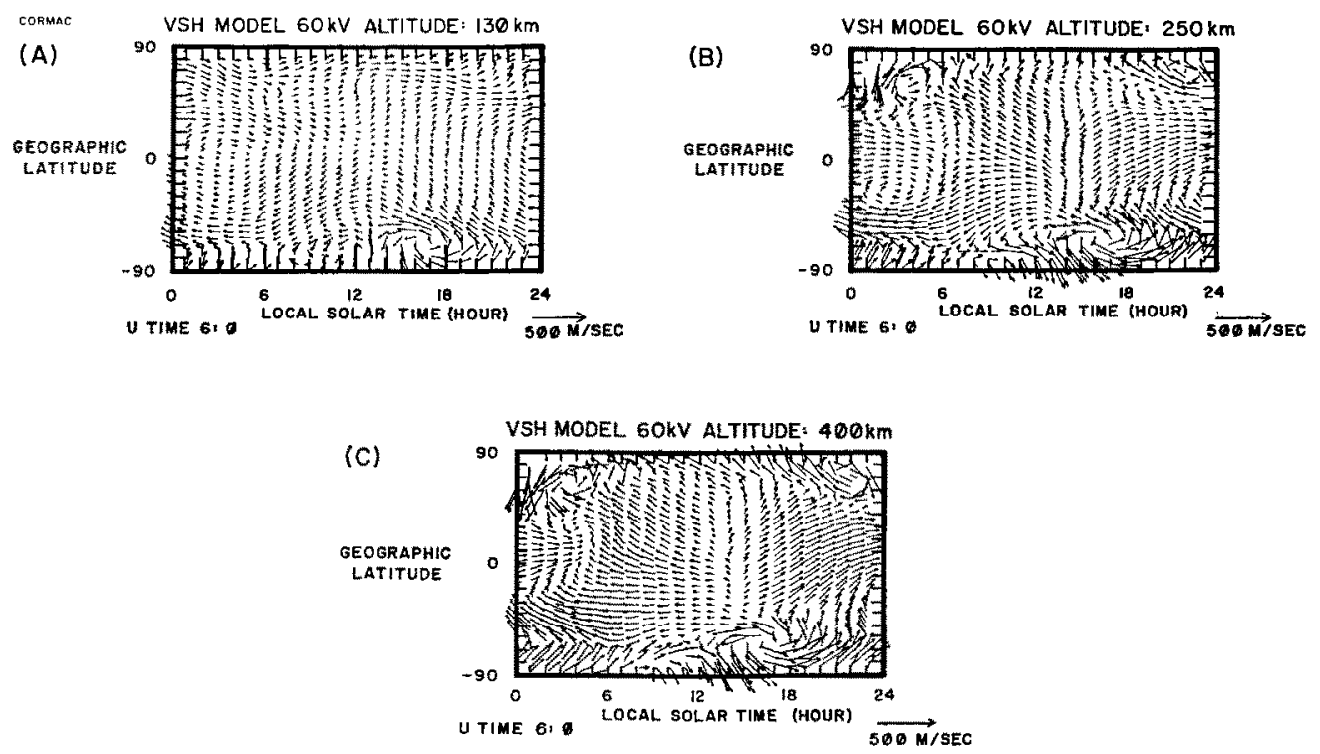

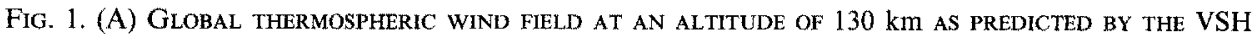
MODEl FOR SOlAR MAXIMUM DECEMBER SOLSTICE CONDITHONS FOR $60 \mathrm{kV}$ CROSSTAL POTENTIAL AT 06:00 $\mathrm{h}$ U.T. (B) VSH WIND FIELD AT $250 \mathrm{~km}$. (C) VSH WIND FIELD AT $400 \mathrm{~km}$.

scale experimental verification is possible, has given confidence in the capability of the TGCM to model the global thermospheric wind system adequately at other altitudes and, therefore, we use the TGCM calculations at all altitudes to provide the wind and temperature profiles used for the FPI measurement simulations. For convenience, the Vector Spherical Harmonic (VSH) representation of the NCARTGCM output, described by Killeen et al. (1987), has been used to provide the wind and temperature fields as a function of U.T., altitude, latitude and longitude using a fast Fortran subroutine. The VSH representation of the TGGM describes the global, threedimensional, time-dependent vector neutral wind field using a vector spherical harmonic expansion in the horizontal, a Fourier expansion in U.T. and a polynomial expansion in altitude. The temperature field is represented by a scalar spherical harmonic expansion in the horizontal, a Fourier expansion in U.T., and a Bates model profile in altitude. Figure 1 shows the global wind fields produced by the VSH model at altitudes of 130,280 and $400 \mathrm{~km}$. The differences between these three vector plots illustrate the altitude dependence of the modelled wind field, which is especially marked at high latitudes.

The atmospheric model used as input to the simulation code also contains a realistic volume emission rate (VER) profile for the $O\left({ }^{\prime} D\right)$ nightglow emission layer. We have used a single profile that was obtained by inverting limb-scan surface brightnesses measured

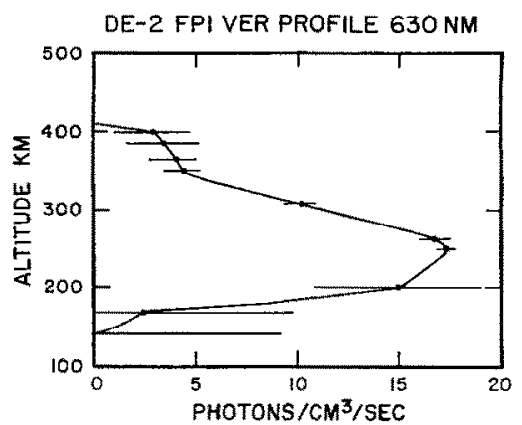

Fig. 2, Volume emission RATE Proflle for the $O(D)$ EMISSION AS OBTAINED FROM INVERSION OF THE LINE-OFSIGHT BRIGHTNESSES OBTAINED BY THE FPI ON THE DE-2 SPACECRAFT.

by the FPI on $D E-2$ (see Fig. 2). This profile acts as a weighting function, determining the contribution that each altitude interval makes to a final wind and temperature measurement. The VER profile was obtained by the $D E-2$ FPI during a period of low magnetic activity $\left(K_{p} \sim 2\right)$ near sunspot maximum and has a peak emission altitude of $\sim 250 \mathrm{~km}$. We have also used the simulation code with other VER profiles (e.g. from Gulledge et al., 1968) and have obtained very similar results to those presented here.

The second element of the simulation code involves the numerical representation of an instrument function. We have not used an idealized instrument function for this work, but have preferred to use a more 
realistic one that incorporates the instrumental defects and sensitivity of a real instrument. The instrument function we have chosen is that of the FPI on $D E-2$ which is described in terms of fourier coefficients (Hays et al., 1981). The response of the FPI to detected radiation originating from an individual thermospheric volume element along the instrumental line-of-sight can be calculated by convolving the numerical instrument function, $\psi(\lambda)$, with a Gaussian source function, $S(\lambda, u, T, \eta)$, representative of the local wind, $u$, temperature, $T$, and surface brightness, $\eta$; here $\lambda$ is the wavelength and $\eta$ is given by the product of the local volume emission rate and the path length through the emitting volume along the line-of-sight. Thus, the response of the FPI to the photons detected from a single volume element along the line-of-sight at an altitude $z$ may be expressed as :

$$
N(z)=\operatorname{CS}(\lambda, u(z), T(z), \eta(z))^{*} \psi(\lambda)
$$

where $N(z)$ is the received signal, $C$ is a constant term describing the sensitivity of the detector, and the symbol * represents the convolution integral.

The third element of the simulation code provides an approximation to the FPI measurement along a given, defined line-of-sight by summing the elemental spectrograms [given by equation (1)] from a finite set of emitting volumes. In this section of the code, the line integral FPI measurement given by:

$$
N_{\text {line-of-sight }}=C \int S(\lambda, u, T, \eta)^{*} \psi(\lambda) \mathrm{d} l
$$

is approximated by the summation :

$$
N_{\text {line-or-sight }}=C \sum_{i=1}^{n} S\left(\lambda, u\left(l_{i}\right), T\left(l_{i}\right), \eta\left(l_{i}\right)\right)^{*} \psi(\lambda) \delta l_{i}
$$

where $l$ is the path length along the line-of-sight and the summation is carried out for $n$ concentric atmospheric layers separated by a given altitude increment. For the results reported here, the altitude increment used was $10 \mathrm{~km}$ and $n$ was set at 25 , with the lowest layer centered on an altitude of $150 \mathrm{~km}$. The path length, $\delta l_{i}$, through each volume element is a function of the zenith angle of the FPI field of view, which was set at $45^{\circ}$ for these simulations.

The fourth element of the simulation code uses a standard FPI data analysis routine (Killeen and Hays, 1984). This routine deconvolves the instrument function from the simulated composite spectrogram, $N_{\text {line- }}$ of-sight, to obtain an effective source function, $S_{\text {eff }}$, characterized by "measured" winds, temperatures, and volume emission rates which reflect the Doppler characteristics of the emission-layer-weighted composite spectrogram. The resulting fitted winds and temperatures are compared with the inputs to the simulation to determine the relationship between the fits and the input exospheric values and to determine the effective altitude of the simulated FPI measurement. In essence, this procedure allows us to test the validity of the standard (but rarely mentioned) assumption that $S_{\text {eff }}$ is equivalent to $S\left(z_{\max }\right)$, where $z_{\max }$ is the peak altitude of the emission layer.

In order to investigate the response of a groundbased FPI instrument sited at any geographic location, we have run the simulation code, described above, for every 5 degrees in latitude and longitude on a global grid. Since the atmospheric model contains global TGCM calculations of wind and temperature profiles, the results illustrate basic differences between the FPI measurement process at auroral and midlatitudes, as well as for summer and winter hemispheres. Limitations to the realism of the simulations are related to the extent to which the NCAR-TGCM provides realistic global profiles of winds and temperatures and the extent to which the input VER profile represents the real $O\left({ }^{\prime} D\right)$ emission profile. The results of the simulations are displayed as global maps of the fitted winds and temperatures as well as the differences between these values and (1) the corresponding input exospheric values and (2) input model values at $250 \mathrm{~km}$.

\section{RESULTS}

Figures $3 \mathrm{a}$ and $3 \mathrm{~b}$ show contour plots of the VSH model exospheric temperatures and the simulated FPI-derived temperatures, respectively, calculated on a 5 global grid at 06:00 U.T. for solar maximum December solstice conditions. The exospheric temperatures, Fig. $3 a$, show the summer hemisphere to be warmer than the winter and the dayside regions to be warmer than the nightside. The same general comments are applicable to the temperature field as calculated by the FPI simulation code, Fig. 3b. However, the simulated ground-based FPI temperaturcs are significantly lower than the VSH model exospheric values. Figures $3 \mathrm{c}$ and $3 \mathrm{~d}$ display this temperature difference as the percentage that the measured temperature is of the input exospheric value and the input model value at $250 \mathrm{~km}$, respectively. Differences are largest (i.e. low percentages) in the summer hemisphere and decrease towards the Northern Hemisphere. In the summer hemisphere, where the vertical temperature gradient predicted by the model is relatively large at the emission peak altitude, the simulation returns temperatures $15-20 \%$ less than the corresponding exospheric temperatures. In the winter hemisphere, where the vertical temperature gradient 


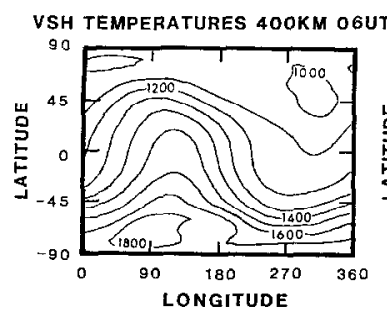

(A)

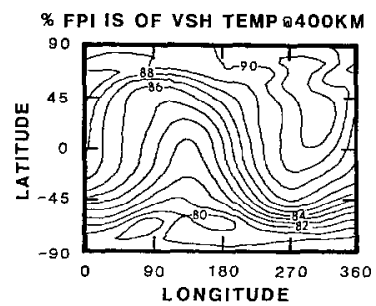

(C)

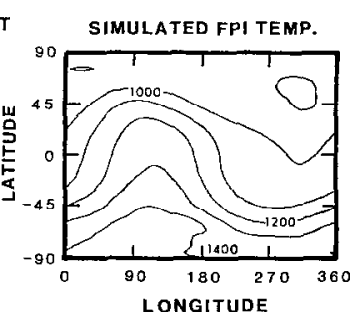

(B)

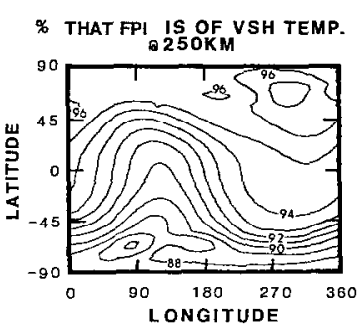

(D)
Fig. 3. (A) CONTOUR Plot OF EXOSPHERIC TEMPERATURES AS PREDICTED BY THE VSH MODEL FOR DECEMBER SOLSTICE SOLAR MAXIMUM CONDITIONS FOR $60 \mathrm{kV}$ CROSSTAIL POTENTIAL AT 06:00 h U.T. TEMPERATURES ARE CalCUlated ON A $5^{\circ}$ GLOBAL GRID. (B) CONTOUR PLOT OF THE TEMPERATURES RETURNED BY THE FPI MEASUREMENT SIMULATION PROGRAM. (C) CONTOUR PLOT SHOWING THE PERCENTAGE THAT THE SIMULATED GROUND-BASED MEASUREMENTS ARE OF TIIE EXOSPIIERIC TEMPerature. (D) Contour plot SHOWIng the PERCENTAGe THAT THE SIMULATED GROUND-BASED MEASUREMENTS ARE OF THE VSH MODEL TEMPERATURES AT $250 \mathrm{~km}$ ALTITUDE.

is relatively small, the simulated values are between 8 and $12 \%$ lower than the exospheric temperatures. Since the percentage differences between exospheric and measured temperatures are least in non-sunlit local time sectors and these are the regions in which ground-based FPIs are operational, the model calculations predict that the difference between a groundbased thermospheric temperature measurement and the actual exospheric temperature should be $\sim 8-10 \%$ for solar maximum conditions. The global percentage differences between the model temperatures and the ground-based simulated values at an altitude of 250 $\mathrm{km}$ are shown in Fig. 3d. The derived and model values differ by only $1-4 \%$, indicating that groundbased FPIs, to a good approximation, measure the temperature at the peak emission altitude in the winter hemisphere. In the summer hemisphere, however, percentage differences between model and simulated temperatures can be as large as $\sim 12 \%$ in night-time sectors.
Figures 4 and 5 show the exospheric wind (i.e. the wind given by the VSH model at $\sim 400 \mathrm{~km}$ ), the simulated FPI-derived wind, and the VSH model winds at $250 \mathrm{~km}$ altitude minus the simulated ground-based winds. These wind fields are displayed in polar coordinates (geographic latitude and local solar time) for Northern and Southern Hemispheres, respectively. The simulated FPI winds are very similar to the model wind field at a height of $250 \mathrm{~km}$, as is indicated by the vector difference plots (Figs $4 \mathrm{~d}$ and $5 \mathrm{~d}$ ). However, they do not represent the exospheric wind field well. Where the difference vectors are small, the agreement is good. The regions where agreement is the poorest are the high latitudes, i.e. in and around the polar cap and in the auroral zones, where relatively large vertical and horizontal wind shears exist. Even in these regions, however, the differences between simulated ground-based FPI measurements and model values at $250 \mathrm{~km}$ are so small as to be of little consequence. Thus, these simulations indicate that ground-based observations at high-latitudes, during solar maximum conditions, should represent the wind field at the peak of the emission layer to within $\sim 2 \%$.

A direct comparison between averaged neutral wind measurements from space and from the ground can be made by referring to the measurements from $D E-2$ and the ground-based FPI at Svalbard, Norway $\left(78.2^{\circ} \mathrm{N}, 15.6^{\circ} \mathrm{E}\right)$ for the month of December 1981 , published by Killeen et al. (1986). The $D E-2$ vector wind measurements were obtained from the $D E$-FPI and the Wind and Temperature Spectrometer, WATS, instruments and have been averaged for all passes occurring within the U.T. ranges 20:00-22;00 h (Fig. 6a) and 22:00-24:00 h (Fig. 6b). The satellite measurements of neutral wind have been discussed by Killeen et al. (1982) and refer to altitudes of $350-400 \mathrm{~km}$, i.e. close to exospheric altitudes. The ground-based averaged wind measurements from the FPI at Svalbard (Smith et al., 1985) are also shown in Fig. 6 for the same U.T. bins. These latter measurements, as we have shown, should be referred to an altitude of $\sim 250$ $\mathrm{km}$ and, therefore, the two techniques sample different thermospheric altitude regions. Since the averaged measurements do not refer to exactly the same geographic location, however, we cannot be sure that the differences in wind speed between the two techniques are not due to their different locations in the velocity field rather than because of the different effective altitudes of the respective measurements. As a consistency check we obtained the VSH model predictions for the vertical profiles of wind speed at the groundstation location for the U.T.S of $21: 00$ and $23: 00 \mathrm{~h}$ and at the positions of the satellite upwind from the ground station at these same U.T.s. These profiles are 
a)

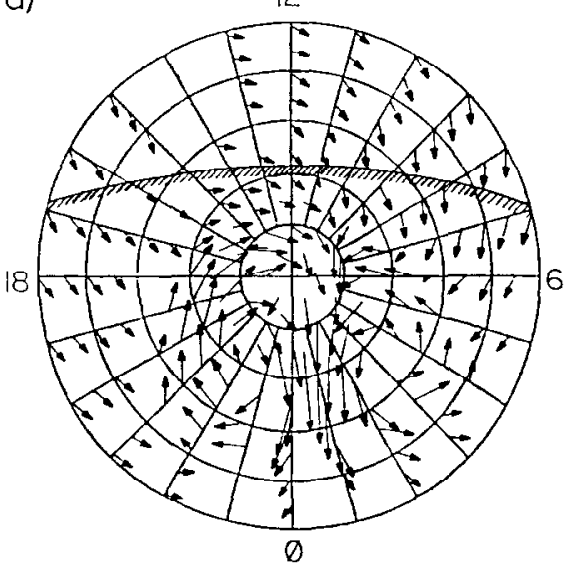

c)

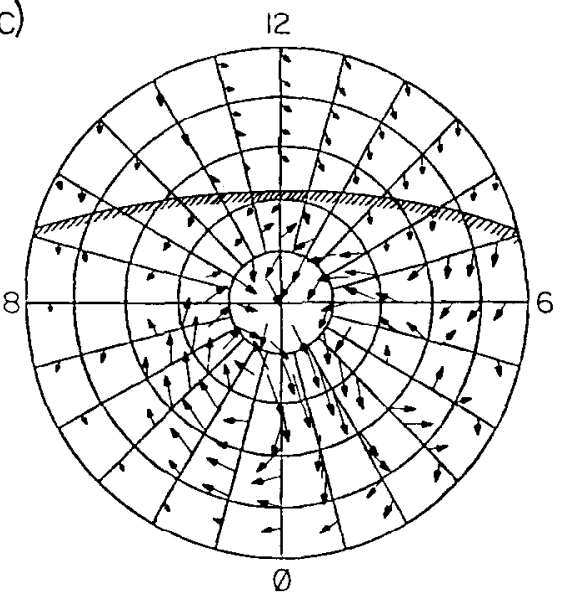

b)

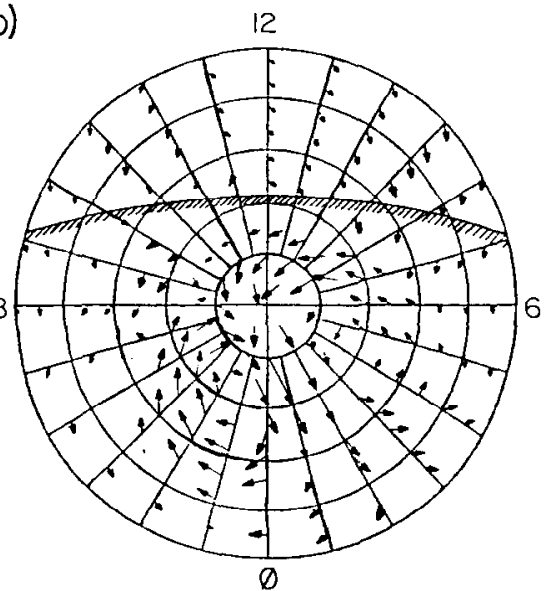

d)

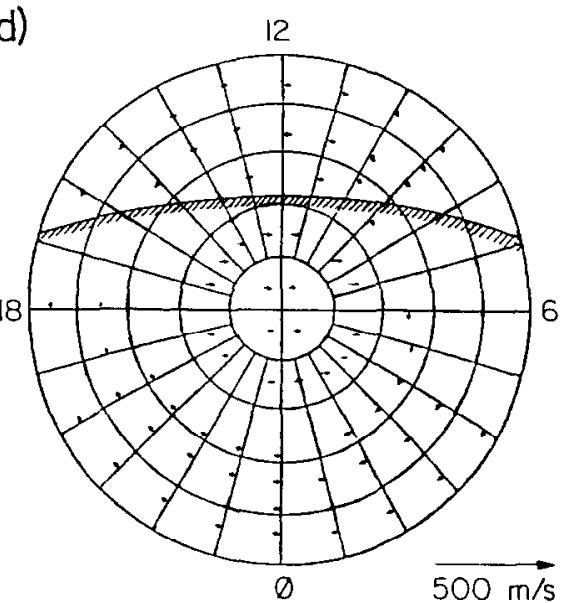

Fig. 4. (a) Polar plot (geographic latitude and local solar time) for the Northern Hemisphere, 40-90 LATITUdE, OF THE NEUTRAL Wind AT AN ALTITUdE OF $400 \mathrm{~km}$ AS GIVEN BY THE VSH MODEL. The plot applies to December solstice solar maximum conditions with a crosstail potential of $60 \mathrm{kV}$ at $06: 00 \mathrm{~h}$ U.T. (b) Polar Plot of Simulated ground-based Measurements of THE THERMOSPHERIC Wind FIELd. (c) Polar plot of the VSH wind field at $250 \mathrm{~km}$ altitude. (d) Polar Plot of the vector difference FIELD OF THE VSH MODEL AT $250 \mathrm{~km}$ AND GROUND-BASED SIMULATED MEASUREMENTS.

shown in Figs $7 \mathrm{a}$ and $7 \mathrm{~b}$ for the 21:00 $\mathrm{h}$ and 23:00 $\mathrm{h}$ U.T. averages, respectively. The model predicts that the "exospheric" wind is greater overhead at the ground station than at the satellite location at 21 U.T. However, the averaged measurements show the satellite to have recorded wind speeds in cxcess of the ground-based measured winds at this time. The model predicts that, at the satellite's altitude, the wind speed should be $340 \mathrm{~m} \mathrm{~s}^{-1}$ whereas the averaged measured wind is $390 \mathrm{~m} \mathrm{~s}^{-1}$. Since the ground-based averaged wind speed measurement is $180 \mathrm{~m} \mathrm{~s}^{-1}$, and this represents $42 \%$ of the expected, normalized value, based on the model predictions, we can use this figure on the model vertical profile of winds to find the height at which $\sim 42 \%$ of the exospheric wind speed occurs. This procedure yields an altitude of $\sim 190 \mathrm{~km}$. A 
a)

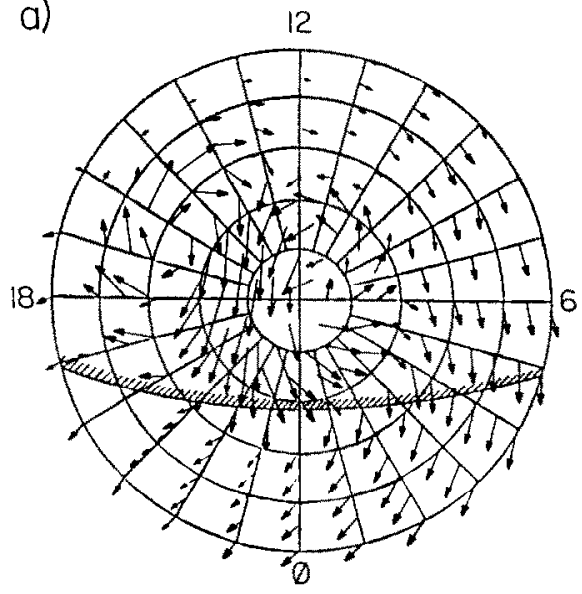

c)

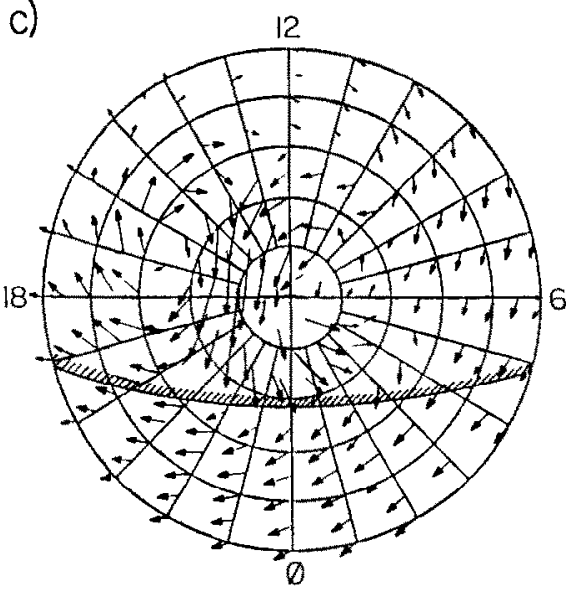

b)

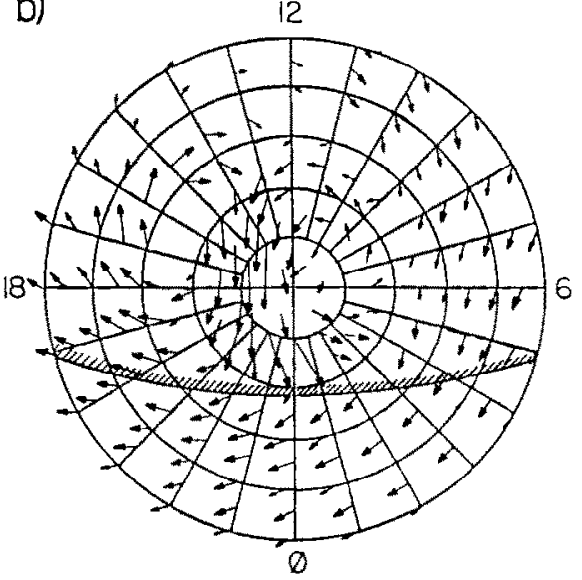

d)

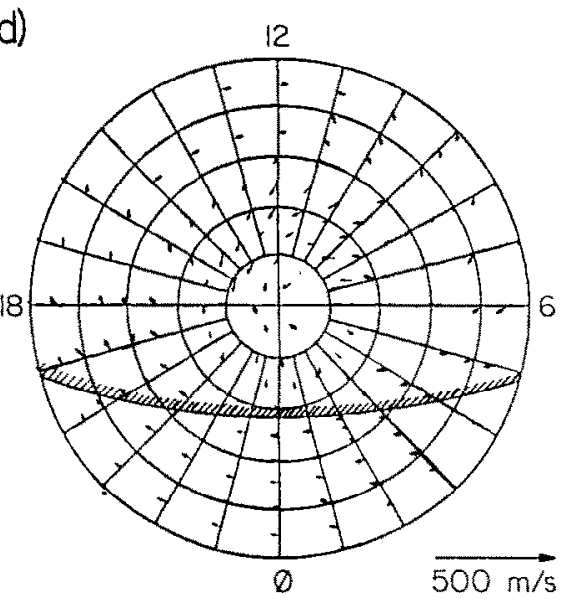

Fig. 5. (a) Polar plot (geographic latitude and local sol ar time) for the Southern Hemisphere, 40-90 LATITUdE, OF THE NEUTRAL Wind AT AN ALTITUDE OF $400 \mathrm{~km}$ AS GIVEN BY THE VSH MODEL. The plot applies to December solstice solar maximum conditions with a crosstail potential of $60 \mathrm{kV}$ at $06: 00 \mathrm{~h}$ U. T. (b) POlar PLOT OF SIMULATED GROUND-BASED MEASUREMENTS OF THE THERMOSPHERIC WIND FIELD.

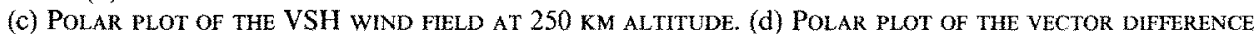
FIELD OF THE VSH MODEL AT $250 \mathrm{~km}$ AND GROUND-BASED SIMULATED MEASUREMENTS.

similar exercise was performed on the data at 23:00 U.T., where the model predicts a greater wind speed at the satellite location than at the ground-based FPI location, and returned an altitude of $\sim 235 \mathrm{~km}$ for the ground-based wind measurement. The two altitudes for the ground-based measurements derived in this way, using the VSH model profiles as a guide, are reasonably consistent with the expected effective altitudes, suggesting that the major differences between satellite and ground-based observations (i.e. the signi- ficantly lesser wind speeds determined from the ground relative to those determined from $D E-2$ ) are due to the different altitudes sampled rather than the differing geographic locations. The two sets of measurements are, therefore, in good agreement with and support the results of the simulation study presented here, by indicating that the ground-based observations provide wind speeds that are significantly smaller in magnitude than those obtained from the spacecraft. 


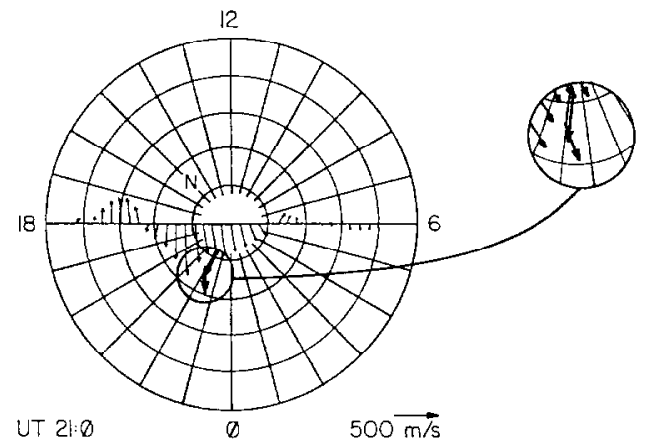

(b)

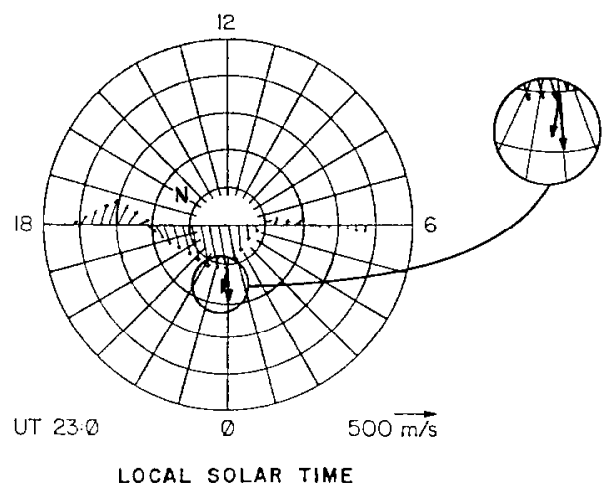

Fig. 6. (a) POLAR Plot (GeOgraPHiC LATITUde ANI) LOCAL SOLAR TIME) OF THE AVERAGED VECTOR NEUTRAL, WINDS AS OBSERVED BY THE FPI ANI WATS INSTRUMENTS ON $D E-2$ AND THE GROUND-BASED FPI AT Longyearbyen, Svalbard (78.2 N, 15.6 E) During the month of December 1981 for the U.T. Range 20:00-22:00 h (KILlEEN et al., 1986). (b) POLAR PLOT OF THE AVERAGED VECTOR NEUTRAL WINDS AS OBSERVED BY $D E-2$ AND THE SVALBaRd FPI DURING December 198I FOR THE U.T. RANGE 22:00-24:00 h.

\section{CONCILISIONS}

We have developed and used a computer simulation model of the measurement process for a ground-based FPI to study how variations of wind and temperature along the instrument line-of-sight affect the Doppler shift and width of the observed $O\left({ }^{\prime} D\right)$ emission line. The major conclusions from the study are applicable to December solstice, solar maximum conditions and are as follows.

(1) Ground-based-derived temperatures in the night-time sector of the winter hemisphere, give values that are representative of the peak $O\left({ }^{\prime} D\right)$ emission altitude. However, when the vertical temperature gradients are large, such as in the summer hemisphere during solar maximum, the ground-based FPI temperature measurement may differ by as much as $\sim 12 \%$ from the temperature at the peak emission height.
(2) Simulations of the FPI measurement of nighttime thermospheric temperatures show that groundbased-derived temperatures may be lower by $\sim 10 \%$ than the corresponding exospheric temperatures in the winter hemisphere and by $\sim 15 \%$ in the summer hemisphere.

(3) Ground-based wind measurements are heavily weighted to the peak emission height of the $O\left({ }^{1} D\right)$. However, the large wind gradients that exist in the thermosphere near solar maximum result in substantial differences (100s of meters per second) between the "exospheric" wind speed and that measured by a ground-based FPI. This is indicated by the simulation calculations and is consistent with previously-reported coordinated measurements made by the $D E-2$ spacecraft and the ground-based FPI at Svalbard, Norway.

Acknowledgements-This work was supported by the National Science Foundation (NSF) via grant numbers 


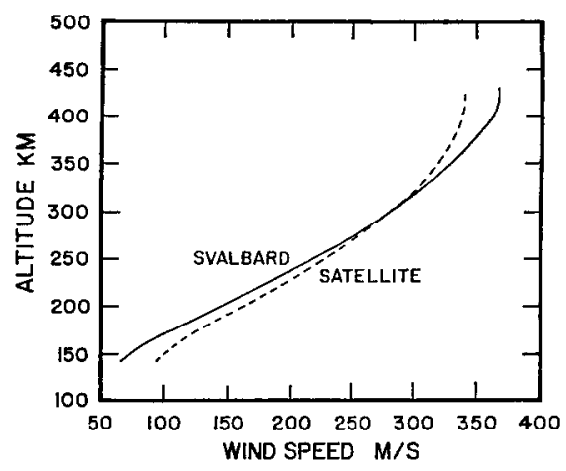

FIG. 7a. VERTICAL PROFILE OF THE WINDS FROM THE VSH MODEL AT THE LOCATION OF THE SATELLITE (DASHED LINE) AND AT THE LOCATION OF THE SVALBARD GROUND-BASED STATION (SOLID LINE) AT 21:00 h U.T.

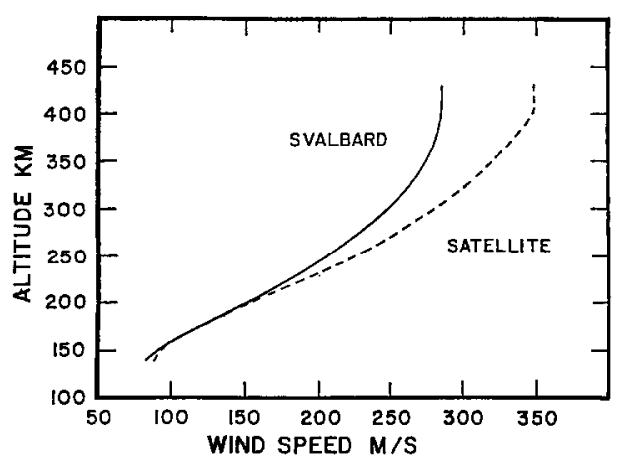

FIG. 7b. VERTICAL PROFILE OF THE WINDS AT THE LOCATION of the SATEllite AND THE SVAlBard STATION AT 23:00 h U.T.

ATM-8412828 and ATM-8610085 and by the National Aeronautics and Space Administration (NASA) via grant number NGA-5-465 to the University of Michigan. Valuable discussions with Drs J. W. Meriwether, Jr., G. Hernandez and R. G. Roble are gratefully acknowledged.

\section{REFERENCES}

Banks, P. M. (1977) Observations of Joule and particle heating in the auroral zone. J. atmos. terr. Phys. 31, 253.

Dickinson, R. E., Ridley, E. C. and Roble, R. G. (1981) A three-dimensional, time-dependent general circulation model of the thermosphere. J. geophys. Res. 86, 1499.

Gulledge, I. S., Packer, D. M., Tilford, S. G. and Vanderslice, J. T. (1968) Intensity profiles of the $6300-\AA$ and $5577-\AA$ OI lines in night airglow. $J$. geophys. Res. 73, 5535.

Hays, P. B., Killeen, T. L. and Kennedy, B. C. (1981) The Fabry-Perot interferometer on Dynamics Explorer. Space Sci. Instrum. 5, 345.

Hays, P. B., Killeen, I. L., Spencer, N. W., Wharton, L. E., Roble, R. G., Emery, B. A., Fuller-Rowell, T. J., Rees, D., Frank, L. A. and Craven, J. D. (1984) Observations of the dynamics of the polar thermosphere. J. geophys. Res. 89, 5597.

Hays, P. B., Nagy, A. F., McWatters, K. D. and Evans, J. V. (1970) Comparison of radar and optical temperature measurements in the $F$-region. J. geophys. Res. 75, 4881.

Hays, P. B., Rusch, D. W., Roble, R. G. and Walker, J. C. G. (1978) The OI $(6300 \AA)$ airglow. Rev. Geophys. Space Phys. 16, 225.

Heelis, R. A., Lowell, J. K. and Spiro, R. W. (1982) A model of the high-latitude ionospheric convection pattern. $J$. geophys. Res. 87, 6339.

Heppner, J. P. (1977) Empirical models of high-latitude electric fields. J. geophys. Res. 82, 1115.

Hernandez, G. (1980) Measurement of thermospheric temperature and winds by remote Fabry-Perot spectrometry. Opt. Eng. 19, 518.

Hernandez, G. and Killeen, T. L. (1987) Optical Measurements of Winds and Kinetic Temperatures in the Upper Atmosphere, Chapter 7, CIRA-86 Model Atmosphere. Pergamon Press, in press.

Hernandez, G. and Roble, R. G. (1979) Thermospheric dynamies investigations with very high resolution spectrometers. Appl. Optics 18, 3376.

Hernandez, G., Van Zandt, T. E., Peterson, V. L. and Turtle, J. P. (1975) Comparison of optical and incoherent scatter measurements of night-time exospheric temperatures at the magnetic equator. J. geophys. Res. 80, 3271 .

Jacchia, L. G. (1965) Static diffusion models of the upper atmosphere with empirical temperature profiles. Smithson. Contr. Astrophys. 8, 9.

Killeen, T. L. (1987) Energetics and dynamics of the Earth's thermosphere. Rev. Geophys. 25, 433 .

Killeen, T. L. and Hays, P. B. (1984) Doppler line profile analysis for a multi-channel Fabry-Perot interferometer. Appl. Optics 23, 612 .

Killeen, T. L., Hays, P. B., Carignan, G. R., Heelis, R. A., Hanson, W. B., Spencer, N. W. and Brace, L. H. (1984a) Ion-neutral coupling in the high-latitude $F$-region: evaluation of ion heating terms from Dynamics Explorer 2. $J$. geophys. Res. 89, 7495

Killeen, T. L., Hays, P. B., Spencer, N. W. and Wharton, L. E. (1982) Neutral winds in the polar thermosphere as measured from Dynamics Explorer. Geophys. Res. Lett. 9, 957.

Killeen, T. L. and Roble, R. G. (1984) An analysis of the high-latitude thermospheric wind pattern calculated by a thermospheric general circulation model, 1. Momentum forcing. J. geophys. Res. 89, 7509.

Killeen, T. L. and Roble, R. G. (1986) An analysis of the high-latitude thermospheric wind pattern calculated by a thermospheric general circulation model, 2. Neutral parcel transport. J. geophys. Res. 91, 11291.

Killeen, T. L., Roble, R. G. and Spencer, N. W. (1987) A computer model of global thermospheric winds and temperatures. Adv. Space Res., in press.

Killeen, T. L., Smith, R. W., Hays, P. B., Spencer, N. W., Wharton, L. E. and McCormac, F. G. (1984b) Neutral winds in the high-latitude winter $F$-region: coordinated observations from ground and space. Geophys. Res. Lett. 11, 311 .

Killeen, T. L., Smith, R. W., Spencer, N. W., Meriwether, J. W., Jr., Rees, D., Hernandez, G., Hays, P. B., Cogger, L. L., Sipler, D. P., Biondi, M. A. and Tepley, C. A. (1986) Mean neutral circulation in the winter polar $F$-region. $J$. geophys. Res. 91, 1633.

Meriwether, W. W., Jr. (1983) Observations of thermospheric 
dynamics at high latitudes from ground and space. Radio Sci. 18, 1035.

McCormac, F. G., Killeen, T. L., Thayer, J. P., Hernandez, G., Tschan, C. R., Ponthieu, J.-J. and Spencer, N. W. (1987) Circulation of the polar thermosphere during geomagnetically quiet and active times as observed by $D E-2$. J. geophys Res. (submitted).

Rees, D., Fuller-Rowell, T. J., Gordon, R., Heppner, J. P., Maynard, N. C., Spencer, N. W., Wharton, L. E., Hays, P. B. and Killeen, T. L. (1986) A theoretical and empirical study of the response of the high-latitude thermosphere to the sense of the " $Y$ " component of the interplanetary magnetic field. Planet Space Sci. 34, 1.

Rees, D., Fuller-Kowell, 'I. J., Gordon, K., Kılleen, 'I. L., Hays, P. B., Wharton, L. E. and Spencer, N. W. (1983) A comparison of wind observations of the upper thermosphere from the Dynamics Explorer satellite with the predictions of a global time-dependent model. Planet. Space Sci. 31, 1299.

Roble, R. G., Dickinson, R. E. and Ridley, E. C. (1982) Global circulation and temperature structure of the thermosphere with high-latitude plasma convection. $J$. geophys. Res. 87, 1599.

Roble, R. G., Dickinson, R. E., Ridley, E. C., Emery, B. A., Hays, P. B., Killeen, T. L. and Spencer, N. W. (1983) The high-latitude circulation and temperature structure of the thermosphere near solstice. Planet. Space Sci. 31, 1479.

Roble, R. G., Emery, B. A., Dickinson, R. E., Ridley, E. C., Killeen, T. L., Hays, P. B., Carignan, G. R. and Spencer, N. W. (1984) Thermospheric circulation, temperature and compositional structure of the Southern Hemisphere polar cap during October-November, 1981. J. geophys. Res. 89, 9057.

Roble, R. G., Hays, P. B. and Nagy, A. F. (1968) Calculated [OI] $6300 \AA$ nightglow Doppler temperatures for solar cycle minimum. Planet. Space Sci. 16, 1109.

Sica, R. J., Rees, M. H., Roble, R. G., Hernandez, G. and Romick, G. J. (1986) The altitude region sampled by ground-based Doppler temperature measurements of the OI $15867 \mathrm{~K}$ emission line in aurorae. Planet. Space Sci. 34, 483.

Smith, R. W., Henriksen, K., Deehr, C. S., Rees, D., McCormac, F. G. and Sivjec, G. G. (1985) Thermospheric winds in the cusp and cleft : dependence on the latitude of the cusp. Planet. Space Sci. 33, 305.

Thayer, J. P., Killeen, T. L., McCormac, F. G., Tschan, C. R., Ponthieu, J.-J. and Spencer, N. W. (1987) IMF $B_{y}$ dependent neutral wind signatures for Northern and Southern Hemispheres from Dynamics Explorer-2 data. Ann. Geophys. (submitted).

Volland, H. A. (1978) A model of magnetospheric electric convection field. J. geophys. Res. 83, 2695. 